\title{
Employees' Outsourcing Perceptions and Satisfaction: The Case of Libya Oil Company
}

\author{
Submitted 21/04/19, $1^{\text {st }}$ revision 13/05/19, $2^{\text {nd }}$ revision 20/06/19 accepted 26/07/19
}

\section{Walid Mohamed ${ }^{1}$}

\begin{abstract}
:
Purpose: The aim of this study is to explore the perceptions of employees working for the Oil Transportation Department of Libya Oil Company regarding their future outsourcing and their current payment satisfaction.

Design/Methodology/Approach : In fact, employees' power has increased dramatically and it cannot be ignored or neglected after the Libyan revolution in February 2011. Despite the fact that outsourcing improves performance, quality, and reduces costs, workers are usually significantly affected within the strategies considered by outsourcing. The literature shows that the employees affected in such outsourcing processes suffer from many problems. The effect of an aggressive culture, such as the Libyan context, on outsourcing employees requires more investigation. One hundred eighty-four workers, from two different operational sites, out of 300, participated in filling in the questionnaire regarding their perceptions of being outsourced to contractors.

Findings: The results show that employees perceive outsourcing negatively, and the results indicate that there is a significant relation between the perceived outsourcing impact on individuals and on profession with their payment satisfaction.

Practical Implications: Management should consider their employees' perceptions as well before outsourcing.

Originality/Value: Executing the strategy of outsourcing employees to contractors seems to be difficult, if not impossible, in an aggressive working environment.
\end{abstract}

Keywords: Outsourcing, perception, individuals, Libya, profession, payment satisfaction.

JEL codes: $H 12$.

Paper Type: Research article.

\footnotetext{
${ }^{1}$ Institute of Graduate Studies and Research, Department of Business Administration, International University, Haspolat, e-mail: Walid.mohamed8188@gmail.com
} 


\section{Introduction}

Outsourcing process is being practiced as a significant strategy by many firms (Zhu, 2016) in order to focus on the core activities by minimizing cost and maximizing profit (Elmuti and Abebe, 2010; Gunasekaran et al., 2015). In addition to cost savings, other advantages can be obtained from outsourcing, an activity minimizing the marketing time (Zhu, 2016) and enhancing the quality of work and creating value (Tsai et al., 2012). For example, when a firm does not have the expertise or skills for a specific work, outsourcing or cooperating with a contractor is considered one of the best solutions. The contractor can help the outsourcer to minimize the logistics time and product improvement time (Zhu, 2016).

Libya Oil Company is one company shared by Libya Africa Investment Portfolio and Libya Oil Holdings which are both owned by the Libyan Government (Libya Oil Structure, 2019). This company is located in Libya. The company's core business is marketing oil products: diesel, kerosene, and lubricants, to end customers through fuel stations by operating these fuel stations as well. In fact, the company owns more than 150 fuel stations all over the country, and more than 100 trucks and semi-trailer fuel tanks in three operating sites. In Libya state, there are four oil products distributors providing the whole country with oil products (Almotawaset, 2018). In fact, when figures of several years reveal that an activity has being generating losses (Libya Oil Company: Financial Annual Reports, 20142018), outsourcing the activity of transporting oil products to specialized companies could be the best solution (Galletti et al., 2010; Min, 2013) in order to save more costs which might be invested in constructing new fuel stations focusing mainly on this core activity. According to Zhu (2016), time, cost, and quality are considered to be the three main aspects for outsourcing management. As the market is becoming more and more competitive, many firms focus on developing and improving the effectiveness of logistics and operations management (Zhu, 2016).

In fact, one of the most important aspect in outsourcing is the workforce factor. Perceptions and reactions of the targeted employees towards outsourcing, before implementing it, seem to be a very important issue to avoid creating chaos (Dolgui and Proth, 2013 ) especially as their power and influence on taking such a decision cannot be ignored. The influence of such employees has increased dramatically especially after the Libyan revolution which took place on February 2011. In fact, most of the previous studies have focused only on perceptions and decisions taken by top management regarding future of affected employees from outsourcing an activity (Butler and Callahan, 2014; Kakabadse and Kakabadse, 2005), and how their attitude was affected after implementing outsourcing (Çiçek and Ozer, 2011). Çiçek and Ozer (2011) add that the effect of an aggressive culture on outsourcing employees requires more investigation. Therefore, the purpose of this study is to investigate employees' perceptions towards being outsourced in the future to 
contractors which should be considered in the decision making of outsourcing the activity of transporting oil products.

\section{Literature Review and Hypotheses Development}

\subsection{Outsourcing}

According to Barthelemy (2003) there are fatal mistakes associated with most failed outsourcing attempts. For example, selecting a wrong contractor, and not dealing with the future of the targeted employees properly are considered significant factors for not making outsourcing project a successful one. According to Kakabadse and Kakabadse (2002) most European and USA firms have revealed that the most preferred solution for the affected employees is to transfer them to contractors or suppliers.

Releasing of workers and employees as a result of redundancies could be either due to changes in strategies, teams, production, or due to decrease in the production planning and the management of the complete process (Stachovál and Stacho, 2013). The ever increasing requirements of the organizations to distinguish themselves against other competitors via strategies, that could bring a variety of service and cost advantages, have really influenced the nature of jobs and have generated new ways of how work should be structured (Tyson and York, 2000).

As outsourcing is considered as a strong cost-oriented, cost minimization strategy in terms of human resources, workers are adopted as a alternative measure for the effectiveness of outsourcing. This measure, in fact, has added a good feature of being both relatively easy and objectively to measure (Kakabadse and Kakabadse, 2002). It can be considered that there is an affirmative relationship between HR levels of outsourcing and the drop in HR employees costs (Abdul-Halim et al., 2016). According to Espino and Robaina (2006), when firms outsource activities to external providers, their previously fixed-labor costs turn into variable costs.

However, Elmuti et al. (2010) found most of the criticisms regarding outsourcing have been mainly in the areas of altering employment arrangements, outsourcing of the labor force, and its influence on organizations and individuals as well. Increase in productivity, in general, is considered to be among the major causes of losing jobs in manufacturing in particular. Outsourcing, by growing productivity, may lead to downsizing. For example, many US organizations like Dell, Avago, and Harley-Davidson technologies considered minimizing their workforce as a part of their outsourcing plans. In fact, the need to minimize the number of workers must not be hidden from the workers of the company and intentions and actions on this issue should be appropriately planned (Stachovál and Stacho, 2013). During the assessment of outsourcing process, managing personnel is very critical. As soon as employees hear about the outsourcing process, most of them may question their skills. Strikes and undesirable reactions are likely to happen, for 
example, counter- productivity (Barthelemy, 2003). According to Barthelemy (2003) keeping the outsourcing process confidential is very difficult. The key to this problem is to make open direct effective communications with all employees within the targeted activity. Benefits must be well illustrated which will result in encouraging and motivating the targeted employees for the outsourcing project (Barthelemy, 2003).

According to Lacity and Hirschheim (1993), workers will be significantly affected by the outsourcing decisions. In fact, concerns related to outsourcing employees are complex on a number of different issues. For instance, the outsourced workers may be assigned to permanently work at the outsourced company's sites, and they might feel that they are committed to both the outsourcing and the outsourced company. Secondly, the contract conditions may lessen job engagement and motivation, and physical and legal restrictions might exist (Andersen and Ankerstjerne, 2010). Elmuti et al. (2010) indicated that the outsourcing project generated two kinds of victims. Workers who have lost their jobs and suffered from some difficulties trying to obtain new employment, and those workers who continued to hold their positions despite the outsourcing decision in minimizing the number of the employees, but they also suffered from some physical and psychological burdens caused by the recent responsibilities of the downsized environment.

Managing workers who have been outsourced is considered to be more challenging. In fact, workers" issues are further more problematical because several customers and workplaces are involved (Elmuti et al., 2010). Often the outsourced employees are functioning remotely from the product or service supplier's offices, and it is common that the service suppliers are forced by the outsourcing company to take on workers who might not fit well with the new company (Andersen and Ankerstjerne, 2010). Studies and researches on the psychological influences of outsourcing have shown that outsourced workers feel increased levels of anxiety.

Usually workers face some difficulties in understanding the new circumstances and situations they are in, and many of them also face difficulties achieving closure because of the need to communicate and coordinate with old colleagues (Andersen and Ankerstjerne, 2010). Feelings of depression, fear, insecurity, anger, quilt, grief, unfairness, reduced motivation and risk taking are expressions and facial signs of survival syndrome (Elmuti et al., 2010). The employees who have not been outsourced are expected to achieve their duties in short period of time, take the additional work, and create new ideas (Elmuti et al., 2010). According to Wood (2009), unless these circumstances and conditions are addressed without delay with an efficient and effective retention plan, it will, definitely, bring extra stress, confusion which will lead to losses in productivity. 
However, the consequences of outsourcing, in fact, are not restricted to loss of capital and unemployment. It could also lead to the deterioration of ethics among employees (Elmuti et al., 2010; Engardio, 2006). Unemployed workers, who have been displaced, have been found to have higher rates of spouse and child abuse, bankruptcy, alcoholism and even divorce (Elmuti et al., 2010; Engardio, 2006). The outsourcing process trend influences workers via the loss of permanentemployment chances and leads to an increasing in the number of contract and parttime employees generally earning less income than permanent employees and, without life, health, and retirement benefits. Charara (2004), for example, has viewed outsourcing activity, in general, as an unconstructive change which would lead to the creation of high levels of frustration and increased the probability of leaving positions.

According to McEvoy and Buller (2013), Kakabadse and Kakabadse (2005), the employees related to the outsourced activity can be either laid off, transferred to suppliers and contractors, and they can be also trained and then deployed to other units within the organization. Within outsourcing arrangements, the provider will employ a major number of employees for one-trial-year (Lacity and Hirschheim, 1993). This action allows the workers to present and prove themselves to the provider before the provider assigns permanent employment. The provider may also ask for performance ratings for every analyst from the customers. If the customers view outsourcing as a good opportunity to eradicate low performers, it may be encouraged to spread this information. However, organizations should also examine the moral implications carefully; "a person's career is at stake" (Lacity and Hirschheim, 1993, p. 3).

On international basis, Kakabadse and Kakabadse (2002) found that for European and USA organizations and firms' the most ideal strategy is to transfer workers to providers and suppliers. The least applied arrangement, slightly more favored by US organizations, is redeployment workers but with new conditions and terms. The results of Kakabadse and Kakabadse (2002) confirmed that outsourcing generates changes for workers, and the general trend highlights changes of the employers, but not essentially change of contracts.

Therefore, in order to make outsourcing process more effective and successful in the future, senior managers should strongly consider adapting some measures in order to prevent some negative developments. These efforts could include "not bulking up on layers of management in times of expansion". Elmuti et al. (2010, p. 22), encouraging lower level workers to participate in some of the organization's decisions, taking advantage of possible opportunities locally and internationally, and conducting training, retaining programs as well as outplacement counseling plans (Elmuti et al., 2010).

In addition, changing the style of management is a very important part of the outsourcing process, especially when workers are transferred. A change in the 
management programs has two main objectives: to cope and control the psychological conditions of the workers, and to make sure that services and products are delivered to the clients without any disruption (Andersen and Ankerstjerne, 2010). Often, the fact is that, too little concentration is being put on the first objective, and, unfortunately, many outsourcing projects have not succeeded as a consequence. Therefore, more emphasis should be put on the first objective (Andersen and Ankerstjerne, 2010).

\subsection{Satisfaction With Pay}

Pay can be defined as the general income gained as forms of rewards which are paid for one's worker and contains all kinds of practical services, financial rewards, and other benefits obtained as part of any employment relationship (Jung and Yoon, 2015). Therefore, payment is the main source of earnings for employees, and because payments can satisfy other needs through income, payment is the key reward (Jung and Yoon, 2015). Balabanova et al. (2016) found that payment satisfaction is considered the most significant method in keeping blue-collar workers in Russia. Similarly, Zin (2017) found that wage satisfaction was directly related to workers' intention to stay. Therefore, the study puts forward the following hypotheses:

\section{H1: Employees' perceptions of future outsourcing on individual are related to payment satisfaction.}

H2: Employees' perceptions of future outsourcing on profession are related to payment satisfaction.

\section{Methodology}

The target of this study consists of the potentially affected employees, who are working in the Department of Oil Transporting of Libya Oil Company. This seems to be very important as their power and influence, on taking such a decision, cannot be ignored especially after the Libyan revolution, which took place on February 2011, which generated violence and chaos all over the country for almost a decade (United Nation, Libya statues, 2018). As working environment has become very aggressive, outsourcing employees requires more investigation in order to avoid negative reactions and financial outcomes. A quantitative research technique has been followed by designing a questionnaire that has been delivered to direct and indirect employees working for the Department of Oil Transporting of Libya Oil Company in three different working sites. The population consists of Tripoli Division which is located in Tripoli, the capital city of Libya State, with 150 direct and 9 indirect employees, Azzawia Division which is $50 \mathrm{~km}$ west of Tripoli, with 100 direct and 6 indirect employees, and Misurata Division which is $200 \mathrm{~km}$ east of Tripoli, with 30 direct and 5 indirect employees. Other divisions, Benghazi and Tubruk which are 1000 and $1500 \mathrm{~km}$ east of Tripoli were not 
included because of the difficulties in obtaining data and information due to the political division of the country.

\subsection{Measures}

The items of the questions were adopted from two sources with slight changes in some words in order to fit the profession. Four questions related to the impact of outsourcing on individuals as well as three questions related to the impact of outsourcing on profession were adopted from Brooks et al. (2009). Whereas two questions measuring employees' current payment satisfaction were adopted from Kennedy et al. (2000). In addition to these measures, demographics were designed to obtain general information and backgrounds of all participants included in the sample. As the original questions were written in English, and the targeted employees speak only Arabic, the process required performing back translation. Back translation is a controversial evaluation process for questionnaire translation which requires - the 're-translation' of already translated questionnaires back into the first language (Behr, 2017). The main point of back-translation is to bring to light any discrepancies between the translation and the source document by making accurate comparison between them (Behr, 2017; Epstein et al., 2015). The questionnaire went through a pilot study which was tested with a number of participants who were similar to those respondents who really completed it (Saunders et al., 2016). The aim of the pilot studying test is to filter the questionnaire in order that the participants will face no problems, such as misinterpretations or ambiguous exclusion or inclusion criteria (Viechtbaue et al., 2015). In addition, the pilot study will allow the researcher to gain some assessment of the validity of the questions as well as the reliability of the data which will be gathered. The pilot study was conducted with ten employees, and all questions were answered without any difficulties within one working day.

\subsection{Sampling Size}

According to Saunders et al. (2016) the sensibility and feasibility of data being collected determine the type of the sampling method. Sample size design is one step which is considered as of the most significant issue in the plan of any questionnaire study (Bonett and Wright, 2011). According to Saunders et al. (2016) for populations of 50 or less, it is usually much more rational to gather data from the whole population where the researcher consider applying probability sampling. Calculating the sample size is considered the hub of any study design (Riechelmann et al., 2018). Sample size determination/estimation refers to the computation of the necessary size of the sample for attaining necessary statistical guarantee of reliability and accuracy of 80 per cent. At the same time justification of the sample size is to give statistical rationalization for the selected size of the sample, which is usually a small figure due to some constraints such as budget and time (Chow et al., 2017). According to Saunders (2016), for almost all management and business research, investigators and researchers are always 
content to calculate approximately the targeted population's features at $95 \%$ certainty. So, accordingly, for this point of the research, the sample size which gives the researcher the minimum level of confidence for the outcome is 168 (total populartion size 300). Five- point Likert scale has been implemented in which number (1) represents "TD" totally disagree and number (5) represents "TA" totally agree.

\section{Results}

The researcher could reach more than $95 \%$ of confidence by obtaining full answered questionnaires by one hundred-eighty four different employees working at two operating sites: Tripoli city site, the capital city of Libya state, and Misurata city site, the third recognized city in Libya. In fact, the results were not surprising for the impact of outsourcing on individuals and profession. However, the results were, to some extent, surprising for employees' current payment satisfaction.

In general, 184 respondents were males as such activity is only employed by males in many countries. North African and Gulf countries for example, unlike Western and Eastern countries in which females work for almost all professions like males. The majority of the respondents were married. Forty three percent of the participants hold secondary school and high school certificate, $28 \%$ have vocational school certificate, $14 \%$ reached primary education, and only $16 \%$ of them have university first degree certificate. However, none of the respondents hold Master or Ph.D. degree. Most of the participants were drivers, and only seven supervisors participated in the survey.

Figure 1. Compares each answered question with the five-point Likert scale

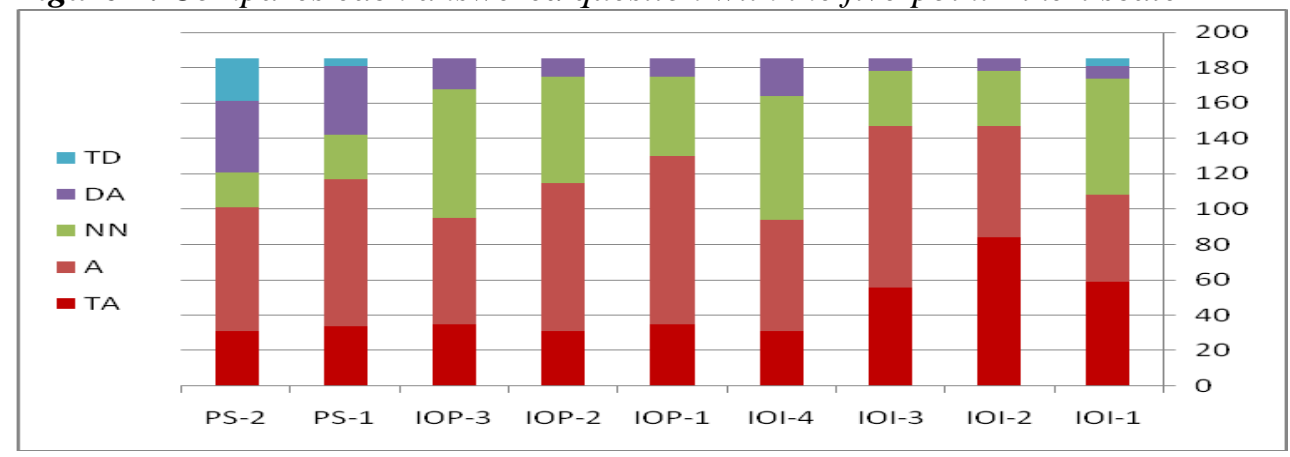

The results of the descriptive analysis indicate that the mean value of employees' perception towards the future impact of outsourcing on individuals was 4,2989 slightly higher than their perception of the future impact of outsourcing on profession which was 3,7699. Whereas, the mean value for the employees' current satisfaction with their payments was almost as the mean value of the future impact of outsourcing on profession, which was 3,6821. 
As shown in the correlation Table 1, the correlation between IOI and PS is significant at 0.01 level, and the association between IOP and PS is also significant at 0.05 level.

Table 1. Illustrates correlations of the variables (IOI, IOP \& PS)

\begin{tabular}{|c|c|c|c|c|}
\hline Variable & \multicolumn{4}{|c|}{ Correlations } \\
\hline & IOI & IOP & PS & NO \\
\hline IOI & 1 & $0,627^{* *}$ & $0,279^{* *}$ & 184 \\
\hline IOP & $0,627^{* *}$ & 1 & $0,155^{*}$ & 184 \\
\hline PS & $0,297^{*}$ & $0,155^{*}$ & 1 & 184 \\
\hline
\end{tabular}

The exploratory factor analysis in Table 2, illustrates that each item is loaded on its underlying construct. However, due to cross loading, two items have been deleted which are related to the impact of outsourcing on individuals. As shown in the Table, the loadings are higher than 0.60 .

Table 2. Illustrates exploratory factor analysis

\begin{tabular}{|c|c|c|c|c|}
\hline \multirow{3}{*}{ (Q) ID } & \multirow{3}{*}{$\begin{array}{l}\text { All Outsourcing and Payment Satisfaction } \\
\text { Questions }\end{array}$} & \multicolumn{3}{|c|}{ Factor Structure Matrix } \\
\hline & & \multicolumn{3}{|c|}{ Component } \\
\hline & & 1 & 2 & 3 \\
\hline Q7 IOP & $\begin{array}{l}\text { Outsourcing can, in the future, negatively } \\
\text { influence career advancement opportunities } \\
\text { for individuals in profession. }\end{array}$ & 1,082 & & \\
\hline Q6 IOP & $\begin{array}{l}\text { Outsourcing can, in the future, negatively } \\
\text { impact the mobility of individuals across the } \\
\text { profession. }\end{array}$ & 0,908 & & \\
\hline Q5 IOP & $\begin{array}{l}\text { Outsourcing can, in the future, cause jobs } \\
\text { across the profession to become less secure. }\end{array}$ & 0,679 & & \\
\hline Q2 IOI & $\begin{array}{l}\text { Outsourcing can, in the future, negatively } \\
\text { impact my mobility in the profession. }\end{array}$ & & 1,023 & \\
\hline Q1 IOI & $\begin{array}{l}\text { Outsourcing can, in the future, negatively } \\
\text { influence my career }\end{array}$ & & 0,885 & \\
\hline Q9 PS & $\begin{array}{l}\text { I am satisfied with my current economic } \\
\text { security, and outsourcing can have negative } \\
\text { effect }\end{array}$ & & & 0,935 \\
\hline Q8 PS & $\begin{array}{l}\text { I am satisfied with my current ability to } \\
\text { maintain an acceptable standard of living, and } \\
\text { outsourcing can have negative effect. }\end{array}$ & & & 0,606 \\
\hline
\end{tabular}

According to Kaiser-Meyer Olkin Measure of Sampling Adequacy (KMO), the result is 0.778 which denotes that the size of the sample was adequate for analysis which give rise that individual factors extracted are reliable and distinct. For the 
Bartletts's test of sphericity, the result has shown that the sphericity was $<0.000$, which means that patterned relationship exists among all items.

Hypothesis (1) which suggests that the impact of outsourcing on individuals (IOI) is related to payment satisfaction (PS) is not rejected since the effect of (IOI) on (PS) is significant and positive $(\beta=0.279, p<.01)$. The results have shown positive support for Hypothesis (2) which tests the association of outsourcing on profession (IOP) with payment satisfaction (PS) $(\beta=0.155, p<.05)$.

\section{Discussion, Implications, Limitations}

Regardless of the aggressiveness of the working environment, the hypotheses and findings regarding employees' perceptions on the impact of future outsourcing on individuals and profession with payment satisfaction are positively related to each other. The descriptive findings actually do support two previous studies in which respondents perceived outsourcing as a negative strategy which would lead to negative consequences on individuals and profession alike (Brooks et al., 2009; Kennedy et al., 2002). According to Zin (2017) pay satisfaction such as bonus and salary, was directly associated with employees' intention to keep working with their current organizations.

Employees are the most important and the most challenging factor for any decision to be taken regarding outsourcing an activity especially in an aggressive environment. The majority of the employees were forced to be transferred from Brega Oil Marketing Company, a national company used to dominate the whole oil distributing and marking in Libya (NOC companies, 2019), to work for Libya Oil Company in 2007. A resolution number (292) issued by Prime Ministry in late 2007, during Gaddafi regime, which resulted in establishing three end-customer oil distributing and marketing companies, aimed to increase quality and control costs (Libya Oil Holdings, 2018). Within this aggressive environment, it seems compelling for the management of Libya Oil Company to apply multi-human resource strategies such as redeployment, redundancy with rewards, fleet acquisition, in addition to outsourcing to contractors.

The questionnaire was designed to obtain answers from employees working at three different sites. However, due to highly security reasons, the researcher could only obtain answers from employees working at two sites who represent $65 \%$ of the total population. Future study should focus on larger sample, and other contexts. Investigation of the association between outsourcing perception and payment satisfaction could be conducted with other sources of data (supervisors).

\section{Conclusion}

Outsourcing an activity effectively, whether core or not, requires time, effort, money, reliable data and perceptions of the workforce, and it can be relatively 
achieved depending on the working environment. However, before outsourcing, employees' feedback should be considered especially when the employees are working in an aggressive environment, and whose actions could affect such decision. Taking into consideration their perceptions regarding being outsourced is vital. Therefore, multi laying of strategies could be taken into consideration instead of a single strategy, such as outsourcing all the targeted employees to contractors, in order to avoid any undesirable outcome.

\section{References:}

Abdul-Halim, H., Che-Ha, N., Geare, A. and Ramayah, T. 2016. The pursuit of HR outsourcing in an emerging economy: The effects of HRM strategy on HR labour costs. Canadian Journal of Administrative Sciences, 33(2), 153-168.

Andersen, M.K. and Ankerstjerne, P. 2010. HR issues to be considered when outsourcing services. ISS and Aspector White Paper.

Balabanova, E., Efendiev, A., Ehrnrooth, M. and Koveshnikov, A. 2016. Job satisfaction, blat and intentions to leave among blue-collar employees in contemporary Russia. Baltic Journal of Management, 11(1), 21-43.

Barthelemy, J. 2003. The seven deadly sins of outsourcing. The Academy of Management Executive, 17(2), 87-98.

Behr, D. 2017. Assessing the use of back translation: the shortcomings of back translation as a quality testing method. International Journal of Social Research Methodology, 20(6), 573-584.

Bonett, D.G. and Wright, T.A. 2011. Sample size requirements for multiple regression interval estimation. Journal of Organizational Behavior, 32(6), 822-830.

Brooks, N.G., Miller, R.E. and Korzaan, M.L. 2009. IT workers on outsourcing: What about me? What about the profession? Journal of ManagementInformation and Decision Sciences, 12(1/2), 1.

Butler, M.G. and Callahan, C.M. 2014. Human resource outsourcing: Market and operating performance effects of administrative HR functions. Journal of Business Research, 67(2), 218-224.

Charara, J. 2004. Impact of outsourcing' lasts years. People Management, 2(4), 15-18.

Chow, S.C., Shao, J., Wang, H. and Lokhnygina, Y. 2017. Sample size calculations in clinical research. Chapman and Hall/CRC.

Çiçek, I. and Ozer, B. 2011. The effect of outsourcing human resource on organizational performance: the role of organizational culture. International journal of business and management studies, 3(2), 131-144.

Elmuti, D., Grunewald, J. and Abebe, D. 2010. Consequences of outsourcing strategies on employee quality of work life, attitudes, and performance. Journal of Business Strategies, 27(2), 177-189.

Engardio, P., Arndt, M. and Foust, D. 2006. The future of outsourcing. Business Week, 30 (January), 50-58.

Espino R, Rodríguez, T.F. and Padrón-Robaina, V. 2006. A review of outsourcing from the resource-based view of the firm. International journal of management reviews, $8(1), 49-70$.

Epstein, J., Osborne, R.H., Elsworth, G.R., Beaton, D.E. and Guillemin, F. 2015. Crosscultural adaptation of the Health Education Impact Questionnaire: experimental 
study showed expert committee, not back-translation, added value. Journal of clinical epidemiology, 68(4), 360-369.

Galletti, D.W., Lee, J. and Kozman, T. 2010. Competitive benchmarking for fleet cost management. Total Quality Management, 21(10), 1047-1056.

Gunasekaran, A., Irani, Z., Choy, K.L., Filippi, L. and Papadopoulos, T. 2015. Performance measures and metrics in outsourcing decisions: A review for research and applications. International Journal of Production Economics, 161, 153-166.

Jung, H.S. and Yoon, H.H. 2015. Understanding pay satisfaction: The impacts of pay satisfaction on employees' job engagement and withdrawal in deluxe hotel. International Journal of Hospitality Management, 48, 22-26.

Kakabadse, A. and Kakabadse, N. 2002. Trends in outsourcing: Contrasting USA and Europe. European management journal, 20(2), 189-198.

Kakabadse, A. and Kakabadse, N. 2005. Outsourcing: current and future trends. Thunderbird international business review, 47(2), 183-204.

Kennedy, J.F., Holt, D.T., Ward, M.A. and Rehg, M.T. 2002. The Influence of Outsourcing on Job Satisfaction and Turnover Intentions of Technical Managers. Human Resource Planning, 25(1).

Kowal, J. and Roztocki, N. 2015. Do organizational ethics improve IT job satisfaction in the Visegrád Group countries? Insights from Poland. Journal of Global Information Technology Management, 18(2), 127-145.

Lacity, M.C., Solomon, S., Yan, A. and Willcocks, L.P. 2011. Business process outsourcing studies: a critical review and research directions. Journal of information technology, 26(4), 221-258.

McEvoy, G.M. and Buller, P.F. 2013. Human resource management practices in midsized enterprises. American Journal of Business, 28(1), 86-105.

Min, H. 2013. Examining logistics outsourcing practices in the United States: from the perspectives of third-party logistics service users. Logistics Research, 6(4), 133-144.

Saunders, M., Lewis, P. and Thornhill, A. 2016. Research Methods for Business Students: Seventh Edition. Person Publications.

Riechelmann, R.P., Araújo, R.L. and Haaland, B. 2018. Sample Size Calculation in Oncology Studies. In Methods and Biostatistics in Oncology. Springer, Cham.

Stachoval, K. and Stacho, Z. 2013. Employee allocation in Slovak companies. Business: Theory and Practice, 14(4), 332-332.

Tsai, M.C., Lai, K.H., Lloyd, A.E., Lin, H.J. 2012. The dark side of logistics outsourcing-Unraveling the potential risks leading to failed relationships. Transportation Research Part E: Logistics and Transportation Review, 48(1), 178.

Tyson, S. and York, A. 2000. Essentials of HRM. Elsevier.

Viechtbauer, W., Smits, L., Kotz, D., Budé, L., Spigt, M., Serroyen, J. and Crutzen, R. 2015. A simple formula for the calculation of sample size in pilot studies. Journal of clinical epidemiology, 68(11), 1375-1379.

Wood, R. 2009. Act now to prevent survivor syndrome. People Management Magazine.

Zhu, X. 2016. Managing the risks of outsourcing: Time, quality and correlated costs. Transportation Research Part E: Logistics and Transportation Review, 90, 121.

Zin, M.L.B.M. 2017. The mediating role of perceived organizational support on the relationship between pay and intention to stay. Management Review: An International Journal, 12(1), 57-68. 